\title{
Dependencies over prosodic boundary tones in Spontaneous Spoken Hebrew
}

\author{
Vered Silber-Varod ${ }^{1,2}$ \\ ${ }^{1}$ The Open University of Israel; \\ ${ }^{2}$ ACLP - Afeka Center for Language Processing, Afeka Tel Aviv Academic College of Engineering \\ vereds@openu.ac.il
}

\begin{abstract}
The aim of the present study is to investigate two aspects of speech: suprasegmental characteristics and syntagmatic relations. More specifically, it focused on the segmentation role of prosody and its interface with the syntagmatic sequence. While certain prosodic boundary tones seem to break speech into coherent syntactic structures, it was found that excessive elongated words are indeed prosodic breaks of various "strong" dependencies. Such a break is not due only to prosody or phonological rules, but can be attributed to the strength of syntactic relations (i.e. dependencies) between the elongated word and the word that precedes it, and between the elongated word and the following word. The findings suggest an encompassing approach to prosodysyntax interface which says that through the elongated boundaries phenomenon, speakers and listeners are exposed to the tension between the prosodic strata and the syntactic strata of language, i.e., between a prosodic break and syntactic continuity. This tension occurs about $10 \%-18 \%$ of spontaneous Israeli Hebrew boundary tones.
\end{abstract}

\section{Introduction}

The hypothesis underlying the study was that prosody and syntax are different levels of speech and therefore prosodic units do not necessarily correspond to syntactic structures. Moreover, while prosodic unit refers in the present research to the intonation unit (IU) (see (Izre'el 2010) for the role of intonation unit in spoken Israeli Hebrew), the term syntactic structures refers to "units or building blocks of different sizes, not just individual words and their [morphological] endings" (Carter and McCarthy 2006, 2). The aim was therefore to find a mechanism that regulates these two levels of human language. The research premise defines prosody as the primary linguistic tool of speech segmentation. Thus, in order to find the regularities underlying the prosody-syntax interface, IU segmentation was carried according to a binary division between perceptually terminal and non-terminal (i.e. continuous) IU boundaries. The present research concentrates on the continuous (C)-boundary inventory in a corpus of spontaneous Israeli Hebrew. The importance of the communicative value of the C-boundary tone is in its linkage function, which will be analyzed according to the syntactic relations between the word preceding and following each of the C-boundaries.

The research will be presented as follows: In \$2 I present the theoretical framework. §3 is dedicated to the methodology taken: The boundary tones in spontaneous Israeli Hebrew are introduced in $\$ 3.1$, and a complex n-gram analysis is explained in $\S 3.2$. In $\$ 4$ I refer to the Israeli Hebrew (IH) corpus and to the issue of word order in IH (\$4.1). The research questions are presented in $\$ 5$. Section 6 presents the results as a mapping between dependency relations and prosodic boundaries. In \$7 I discuss the connection between form (prosodic boundary tones) and function, using Dependency Grammar (DG) terminology of head and dependent; while in $\$ 8 \mathrm{I}$ present the [+dependency] feature in order to explain the results.

\section{Theoretical framework}

The segmentation of speech into intonation units allegedly encompasses several types of prosodic units in the prosodic hierarchy which are above the PrWd level: the phonological phrase, the intonational phrase and the utterance (Selkirk 1995), which are "to a large extent ... similar to syntactic structures" (Anderson 2005, 68). Steedman (2001) claims that "surface structure and information structure coincide, the latter simply consisting in the interpretation associated with a constituent analysis of the sentence. Intonation in turn coincides with surface structure (and hence information structure) in the sense that all in- 
tonational boundaries coincide with syntactic boundaries..." (Steedman 2001, 652).

The analysis below attempts to answer the following question: How can evidence of continuous boundary tones, which are actually prosodic breaks, within syntactic units such as clause or phrase, be explained linguistically? The answer will use the notion of heads in grammatical theory: "the idea that one word may dominate another - that a subordinate word depends on a head word - is the central insight of traditional dependency grammar and its more recent offspring" (Fraser, Corbett, and McGlashan 1993, 3). Yet, the syntactic priority adopted in most of the theoretical approaches is increasingly disclaimed as evidence for the grammaticalization of spontaneous speech phenomena, like hesitations, self-repair or false-starts emerge in Hebrew and in other languages (Fox, Maschler, and Uhmann 2006). Thus, the main concern is to find a syntactic approach that can deal with "hesitations" or what is called here excessive elongation phenomenon and that is able to classify syntactically the elongated POSs, mainly function words. This goes hand in hand with Selkirk (1995), who claims that "the question of how many levels of phrasing there are in the universal Prosodic Hierarchy turns out not to be relevant to the prosodic analysis of function words." (Selkirk 1995, 5).

DG (inter alia Hudson 1993; 1996) seems to be adequate since its main concern is relations between words, or a pair of elements on the same level in a sentence, such as the relation of the subject to the predicate or of a modifier to a common noun. Moreover, the syntaxprosody interface was already studied in Mertens (2011) "sur la notions de dependance, ..." (Mertens 2011, p. 20). To this end, the terms head and dependent as well as the notion of dependency between words will be used.

The main relevant notions in DG to the present study are the following: DG is a grammar in which syntactic structure is expressed primarily in terms of dependency relations. One of the elements depends morphologically, syntactically, or semantically on the other. Dependency relations contrast with constituency relations which hold between elements on different levels of a sentence (Fraser 1996, 71). In DG, the syntactic structures "are represented by dependency trees or sets of nodes whose inter connections specify structural relations, i.e., a governor controls its de- pendents by dependency rules which specify the correct structural relations for each class of unit" (Brown and Miller 1996, 397; illustrated in Fraser 1996, 72). According to Brown and Miller (1996), "in contrast with constituent structures, functional structures focuses on, not arrangements of constituents, but the relationships between constituents" (1996, xiii). Schneider (1998) notes that of the models that take the functional relations as primary, "the most syntactic" is DG, in which relations such as 'head' and 'modifier' are primary. One of the principles that he mentions concerns the syntactic duality that exists in a single word: "What is important in DG is the ability to analyze words at both levels, structural and linear: dependency is a grammar in which individual words both act as terminal nodes and as nonterminal nodes. They are terminal because they directly access the lexicon, because in its purest form, dependency only knows words; and they are non-terminal because they "require", they "subcategorize for" other words, so-called dependents." (Schneider 1998, 7).

\section{Method}

\subsection{Prosodic annotation and distribution}

As mentioned above, the present study is concerned with syntactic relations over continuous prosodic boundary tones. A boundary tone was perceptually annotated as Continuous (C) whenever the final tone of the intonation unit signaled "more to come". This annotation is primarily based on perception of the author and according to the prosodic segmentation rules described in Izre'el and Mettouchi (forthcoming: 11-19). Yet, over $15 \%$ of the corpus were similarly annotated and proofed by other researchers in several other studies (inter alia Izre'el 2005).

Continuous boundary tones were further divided into five sub-sets, and their manual annotation was carried using acoustic cues. The five C-boundaries are: Continuous Rising $(\mathrm{C} \uparrow$ ) tone (14\% of C-boundaries), ContinuousFalling $(\mathrm{C} \downarrow)$ tone (5\%), Continuous RisingFalling $(\mathrm{C} \uparrow \downarrow)$ tone $(6 \%)$, Continuous Neutral $(\mathrm{C} \rightarrow)$ tone $(33 \%)$, and Continuous Elongated (C:) tone (42\%). This last C: boundary tone was defined phonetically and phonologically in Silber-Varod (2010). It should be mentioned that C-boundaries are only $29 \%$ of prosodic boundaries in the corpus. Terminal boundaries 
consist of $66 \%$ and truncated IUs consist of $5 \%$.

\subsection{Linear (n-gram) analysis}

The present research uses linear analysis called $n$-gram. An $n$-gram model considers the probability of $n$ items occurring in sequence, i.e., it is a type of probabilistic model for predicting the next item in a sequence. The probability calculation was performed on trigrams (a sequence of 3 items). The items analyzed were trigram of $\mathrm{ApB}$ sequences, where $\mathrm{A}$ and $\mathrm{B}$ are Parts-of-Speech and $\mathrm{p}$ is a C-boundary type (one of the five C-boundaries introduced in §3.1). The annotations included 36 Parts of Speech (syntax) and five C-boundaries (prosody). All annotations were manually performed on the words that precede and follow each Cboundary. Conditional probability processing was performed by AntConc software (Anthony 2007).

For example, in the string in (1) (first line is SAMPA for Hebrew transcription; the second is the translation), which includes two Cboundaries, only the underlined sequences were annotated and calculated. ${ }^{1}$

(1) az amaRti la Se C: etmol halaXti le Xatuna $\mathrm{C} \uparrow \downarrow$ az keilu ... [D631]

'so I told her that C: yesterday I went to a

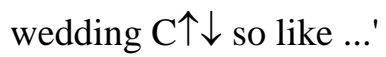

Thus, two trigrams were extracted from (1) to the trigram inventory:

COMP C: ADV

$\mathrm{NC} \downarrow \downarrow \mathrm{DM}$

where COMP is the subordinate particle [Se] 'that'; ADV for adverbs, such as [etmol] 'yesterday'; $\mathrm{N}$ for nouns, [Xatuna] 'wedding' in the second underlined sequence in (1); and DM for discourse markers, [az] 'so'.

It should be noted that an automatic dependency parser of Israeli Hebrew was developed by Goldberg (In progress. See also Goldberg and Elhadad 2010). Goldberg's (In progress) Easy-First parser process sentences written in Hebrew orthography, and was trained on a daily Israeli newspaper. In the present study, the analysis and annotation were carried directly over the transcriptions of spontaneous speech.

Part-of-Speech tagging in this study is based on the list of standard abbreviations in the
Leipzig Glossing Rules. Yet, additional ad hoc tags were used in the present study, such as PREP-DEF which represents the definite article /ha/ 'the' which is morphologically attached to two possible prepositions /be/ 'in, at' and /le/ 'to'. This combination of the two lexemes creates two monosyllabic CV structures, with the first consonant of the preposition and the [a] vowel of the definite article: /ba/ 'in the' and /la/ 'to the', respectively.

\section{Data}

The corpus used in this research contains 19 audio segments from 19 recordings that were selected from CoSIH - Corpus of Spoken Israeli Hebrew. The recordings, which were made during 2001-2002, are of authentic Israeli Hebrew everyday conversations. Each dialogue consists of conversations between one core speaker and various interlocutors with whom the speaker interacted on that day. The research corpus consists of 31,760 word-tokens (over 6 hours of speech) of which 4,289 are word-types. All recordings were manually transcribed according to SAMPA (Speech Assessment Methods Phonetic Alphabet).

The prosodic boundary tone inventory consists of 9,400 annotated boundary tones. The present research focus on the 2,775 Cboundaries (see $\$ 3.1$ above).

\subsection{Israeli Hebrew word order}

Among the 'basic orders' found in languages of the world, Hebrew is said to prefer a SVO word order. Nevertheless, Israeli Hebrew word order is relatively free and all possible alternatives can appear in specific contexts, e.g. literature and poetry.

Several standard issues are mentioned with respect to $\mathrm{IH}$ word order: Adjectives always follow the nouns and numerals they modify, with exception of the numeral 'one' that always precedes it. Definite nouns are preceded by the definite article [ha] 'the', which also appears in the modifying adjective [ha-banana hatsehuba] (lit. the-banana the-yellow) 'the yellow banana'. Prepositions also appear at the head of the phrase. The conjunctive marker [ve] 'and' appears before the last element in the list and the subordination marker [Se] 'that' appears before the subordinate clause. Question words such as [mi] 'who', [ma] 'what',

In several defined cases, the sequences were wider. 
[mataj] 'when', [efo] 'where', appear at the beginning of the phrase, in standard Hebrew.

Like other Semitic languages, the isomorphic connection between phonology, morphology, syntax and semantics is much more overt when compared with the Indo-European languages. The vast majority of the words of the language can be analyzed into consonantal roots signaling broad semantic fields. These roots are combined with fixed morphophonemic patterns for what is traditionally called nominal, verbal, and adjectival forms. Nouns in $\mathrm{IH}$ exhibit prosodic and vocalic restrictions called mishkal ('weight').

In the verb system, Israeli Hebrew morphology is characterized by the non-concatenative Semitic type structure. A verb must belong to one of the five to eight morphological classes called binyanim ('constructions'). Verbs are also accompanied by affixes indicating tense, person, number, and gender. Rosén (1977) suggested considering the preposition as forming one constituent together with the verb: "The preposition constitutes the government properties of the verb" (Rosén 1977, 169-170). Rosén presented an example of the prepositions /le/ 'to', /be/ 'in' and /al/ 'on', and noted that, with the occurrence of certain verbs, these prepositions have no substitution, and function as cases (such as the accusative case marker [et] 'Acc.').

Nevertheless, Hebrew, as a "non-strict word-order" language, does not allow clitics and affixes at the phrase final position. Thus, the preposition stranding phenomenon does not occur in Hebrew. This characteristic of Hebrew means that we will not find prepositions in clause final position or in phrase final position (although this syntactic constraint is overruled in case of few coined idioms).

\section{$5 \quad$ Research questions}

The research seeks to determine what are the most probable POSs at each of the Cboundaries environment, and to see if there is a difference in the dependency distribution among C-boundaries. For example: Is a Cboundary, notably $\mathrm{C}$ :, a repetition domain or a repair domain, thus finding the same POS before and after the C-boundary might serve as a clue, or is it a prosodic "bridge", in which case we would expect to find dependent POS, and C-boundaries occurring within a clause? Alternately, do we find clues to the ends of clauses before C-boundaries, so that we can assume that $\mathrm{C}$-boundaries are only minor prosodic breaks between clauses? And, of course, is there an inherent difference between the different C-boundaries, as implied by example (1) above?

\section{Results}

In this section, the results of both the preceding and the following POS attachments to Cboundaries will be described, in order to examine whether any relations exist between the POSs on the two sides of the C-boundary. These a-priori relations are called dependencies in this research, since it is assumed that Cboundaries connect dependent words (e.g., a head and its dependent(s)).

The first stage was to find regularities. This was achieved by analyzing trigrams (see $\$ 3.2$ ) in terms of the number of repetitions and probability. After a clean-up procedure, which excluded unintelligible words, and "isolated" disfluencies, i.e. disfluencies between pauses, 2,517 sequences of "POS C-boundary POS" trigrams were examined. Of these, 962 are trigram types, of which 502 (52\%) are singleton (unique) trigrams.

Table 1 shows three parameters of analysis: occurrence; conditional probability (of the first $\mathrm{POS}$ in the trigram sequence, given the two following items: C-boundary and the following POS) $;{ }^{2}$ and (assumed) syntactic dependency. The table is arranged according to probability (descending order) and it shows the 13 most probable and most frequent trigrams (The next most probable trigrams are with less than 10 occurrences).

The primary tendencies shown in Table 1 are the following: In terms of prosody, it is evident that $C$ : boundaries show more regularity than other C-boundaries -9 cases vs. 3 cases of $\mathrm{C} \rightarrow$ and a single case of $\mathrm{C} \uparrow$, while the two other C-boundaries are not even in the list. It is also evident that the two level boundary tones, $\mathrm{C}$ : and $\mathrm{C} \rightarrow$, are substantial in terms of regularity.

In terms of POS preceding the $\mathrm{C}$ boundaries, it is evident that all 9 cases of $\mathrm{C}$ : have a POS of the closed class, e.g. definite article, preposition, personal pronoun. The preceding POS to $\mathrm{C} \rightarrow$ and $\mathrm{C} \uparrow$ are of the open

\footnotetext{
${ }^{2}$ I would like to thank Yoav Goldberg for his assistance with the probability calculations.
} 
class, i.e., adjectives and nouns (lines 4, 10, 13). Although a single case of preceding POS to $\mathrm{C} \rightarrow$ is a pronoun (line 6), which belongs to the closed class, it was found that its "dependency" type is inherently different than the all dependencies over $\mathrm{C}$ : (see example in Table 1line 6).

In terms of POS following the C-boundaries in Table 1, it is evident that only conjunctions follow $\mathrm{C} \rightarrow$ and $\mathrm{C} \uparrow$ (lines 4, 6, 10, and 13). POSs that follow $\mathrm{C}$ : are mostly of the open class (lines 1-3, 7, and 9), and the rest four are of the closed class.

This closed vs. open class categorization was found useful for the generalization attempts to find regularities of dependencies over C-boundaries, as is demonstrated in the five dependency types found:

1. Five cases of dependencies are within coordination structure. These dependencies are of two types, syndetic coordination or simply juxtaposed (a-syndetic coordination). In the present study, the syndetic coordination is either when the CONJ follows the C-boundary (lines 4, 6, 10 and 13), or when the CONJ precedes the C-boundary, mainly C: (line 12). Asyndetic construction appeared within enumeration dependency (not one of the most probable cases presented in Table 1).

2. The dependency in line 10 reflects the most frequent trigram in the corpus " $\mathrm{N} \mathrm{C \rightarrow}$ CONJ", which occurs 52 times.

3. Three cases are assumed dependencies within phrases: the dependencies within NPs are of a definite article and a noun (lines 1,2); the dependencies within PPs are of a preposition and a noun (line 3 ).

4. Two are dependencies between a subject and a predicate (lines 7 and 9).

5. Two cases show no dependency but an assumed repetition (lines 5 and 8 ).

6. A single case shows no dependency but an elongated discourse marker (line 11) with a following personal pronoun, which is assumed to be the subject in a new clause.

The results, partly presented in Table 1, demonstrate how preceding POSs can be predicted with respect to C-boundaries. This reflects the fact that a rather restricted group of closed set POSs appears before C: boundary tone, compared to a rather varied, open class, group of POSs with each of the four other Cboundary tones.

Considering the following POSs, the results demonstrate, again, the similarity, in terms of POS attachment, between these four Cboundaries $-\mathrm{C} \uparrow, \mathrm{C} \rightarrow, \mathrm{C} \uparrow \downarrow, \mathrm{C} \downarrow-$ and the unique case of the $\mathrm{C}$ : boundary. Only three POSs were found after the four C-boundaries: PRP, CONJ and DM. On the other hand, N was the POS most likely to appear after C:.

To sum up the results, the dependencies can be scaled according to their "strengths":

1. No dependency: The weakest dependency is when a C-boundary does not split a syntactic dependency. This occurs when a new start begins after the C-boundary and is common to all 4 boundaries: $-\mathrm{C} \uparrow, \mathrm{C} \rightarrow$, $\mathrm{C} \uparrow \downarrow, \mathrm{C} \downarrow$. The other type is when a $\mathrm{C}$ boundary follows discourse markes - this is typical of C: boundaries.

2. Within coordination construction: A stronger dependency occurs when a coordination structure is observed. This dependency is divided into two types which affect the C-boundary distribution. When the conjunction follows the C-boundary, it is more likely that $\mathrm{C} \uparrow, \mathrm{C} \rightarrow, \mathrm{C} \uparrow \downarrow, \mathrm{C} \downarrow$ will occur. When the conjunction precedes the $\mathrm{C}$ boundary, it is most probable that the C: boundary will occur. This case can also be considered as discourse marker case, i.e., no dependency case, since the most frequent conjunctions [ve] 'and' and [aval] 'but' function as such in Israeli Hebrew (Fox, Maschler, and Uhmann 2006).

3. Between a subject and a predicate: C: boundaries are more likely to occur within this dependency.

4. Within phrases: This is the "strongest" dependency that C-boundaries break, and it is most likely that $\mathrm{C}$ : boundaries will occur here.

Although only $\sim 30 \%$ of the prosodic boundaries in the corpus are C-boundaries, (see \$3.1), the results suggests they seem to play a significant role in spoken $\mathrm{IH}$, while C: boundary tone is a marked continuous boundary tone, since it regularly "breaks" grammatical dependencies. 


\begin{tabular}{|c|c|c|c|c|}
\hline & $\begin{array}{|lll|}\begin{array}{l}\text { Preceding } \\
\text { POS }\end{array} & \begin{array}{l}\text { C- } \\
\text { boundary } \\
\text { tone }\end{array} & \text { Following POS } \\
\end{array}$ & Occurrences & Probability & $\begin{array}{l}\text { Assumed dependency and a } \\
\text { typical example }\end{array}$ \\
\hline \multirow[t]{2}{*}{1} & definite article $\quad \mathbf{C}$ : & 43 & 0.413 & $\begin{array}{l}\text { Within the nominal chunk of } \\
\text { NP }\end{array}$ \\
\hline & $\begin{array}{l}\text { lehavin et ha } \mathrm{C}: \text { \# et ha } \mathrm{C}: \text { \# tiskul [C412] } \\
\text { to understand ACC the } \mathrm{C}: \text { \# ACC the } \mathrm{C}_{\mathbf{i}} \text { \# frustration } \\
\text { 'to understand the the frustration' }\end{array}$ & & & \\
\hline \multirow[t]{2}{*}{2} & PREP-DEF & 16 & 0.333 & $\begin{array}{l}\text { Within the nominal of NP } \\
\text { (within PP) }\end{array}$ \\
\hline & 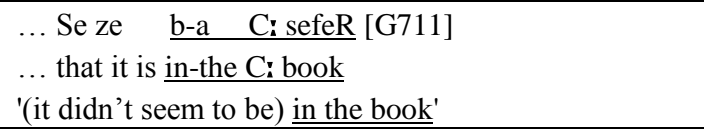 & & & \\
\hline \multirow[t]{2}{*}{3} & preposition & 26 & 0.224 & Within PP \\
\hline & 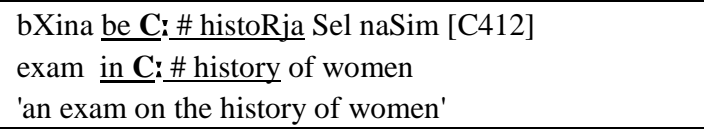 & & & \\
\hline \multirow[t]{2}{*}{4} & adjective $\quad \mathbf{C} \rightarrow \quad$ conjunction & 17 & 0.157 & Within coordination structure \\
\hline & $\begin{array}{l}\text { ze lo holeX lihjot maSehu mesubaX } \mathrm{C} \rightarrow \mathrm{ki} \text { hem lo hol } \\
\text { 'it is not going to be too complicated } \mathrm{C} \rightarrow \text { since they wi }\end{array}$ & $\begin{array}{l}\mathrm{m} \text { lehaSkia jote } \\
\text { not invest too } \mathrm{m}\end{array}$ & $\begin{array}{l}\text { midaj be mas } \\
\text { Ich in alcohol' }\end{array}$ & kaot [D341] \\
\hline \multirow[t]{2}{*}{5} & preposition & 17 & 0.147 & Repetition \\
\hline & $\begin{array}{l}\text { meaSeR li-Xjot be } \mathbf{C}: \text { be hitnagSut kol ha zman }[\mathrm{C} 111 \\
\text { than to-live } \underline{\text { in } \mathbf{C}}: \text { in conflict all the time } \\
\text { 'than living in conflict all the time' }\end{array}$ & & & \\
\hline \multirow[t]{2}{*}{6} & $\begin{array}{lll}\text { pronoun } & \mathbf{C} \rightarrow & \text { conjunction } \\
\end{array}$ & 12 & 0.138 & Within coordination structure \\
\hline & $\begin{array}{l}\text { halaX hisgiR- } \varnothing \text { et } \\
\text { go.PST.3SG. turn_in.PST-3SG ACC himself } \mathrm{C} \rightarrow \text { and } \\
\text { '(he) turned himself in and was imprisoned for a short t }\end{array}$ & $\begin{array}{l}\text { IV- } \varnothing \text { mamaS kts } \\
\text { PST-3SG reall } \\
\mathrm{e}^{\prime}\end{array}$ & $\begin{array}{l}\text { zman }[\mathrm{C} 1621 \\
\text { little time }\end{array}$ & \\
\hline \multirow[t]{2}{*}{7} & $\begin{array}{lll}\begin{array}{l}\text { personal pro- } \\
\text { noun }\end{array} & \mathbf{C}_{\mathbf{:}} & \text { verb } \\
\end{array}$ & 18 & 0.129 & $\begin{array}{l}\text { Between subject and predi- } \\
\text { cate }\end{array}$ \\
\hline & $\begin{array}{l}\text { ve hi } \mathbf{C}: \text { amR-a } \\
\text { and she } \mathbf{C}: \text { tell.PST-3SG.F me that she go.PTCP.SG.F } \\
\text { 'and she told me that she was going to sleep' }\end{array}$ & sleep & & \\
\hline \multirow[t]{2}{*}{8} & C: $\quad$ conjunction & 21 & 0.124 & Assumed repetition \\
\hline & $\begin{array}{l}\text { aval e } \mathbf{C}: \text { \# imm miSehu ja-XziR [D741] } \\
\text { but eh } \mathbf{C}_{\mathbf{i}} \text { \# if someone 3SG.M-FUT.return } \\
\text { 'but eh if someone will return [something]' }\end{array}$ & & & \\
\hline \multirow[t]{2}{*}{9} & \begin{tabular}{|l|l|l|}
$\begin{array}{l}\text { personal pro- } \\
\text { noun }\end{array}$ & C: & participle \\
\end{tabular} & 17 & 0.122 & $\begin{array}{l}\text { Between subject and predi- } \\
\text { cate }\end{array}$ \\
\hline & $\begin{array}{l}\text { az hem C: mizdakn-im tl- neXlaSim ve noflim T [OCh } \\
\text { so they } \text { : old.PTCP-PL.M @ - weak.PTCP.PL.M and } \\
\text { 'so they are getting old @ - getting weak and falling do }\end{array}$ & 1.PTCP.PL.M & & \\
\hline \multirow[t]{2}{*}{10} & $\mathbf{C} \rightarrow \quad$ conjunction & 52 & 0.118 & Within coordination structure \\
\hline & $\begin{array}{l}\text { kol jom medabRot ba telefon } \mathrm{C} \rightarrow \text { ve nifgaSot ve hakol } \\
\text { 'every day (they) talk on the phone } \mathrm{C} \rightarrow \text { and meet and } \mathrm{e}\end{array}$ & $\begin{array}{l}\text { S1241] } \\
\text { rything' }\end{array}$ & & \\
\hline \multirow[t]{2}{*}{11} & $\begin{array}{lll}\begin{array}{l}\text { discourse } \\
\text { marker }\end{array} & \text { C: } & \text { personal pronoun } \\
\end{array}$ & 21 & 0.114 & None \\
\hline & $\begin{array}{l}\underline{\text { zot_omeRet e } \mathbf{C}}: \text { at } \quad \text { pogeSet kaXa anaSim [C4 } \\
\underline{\text { I_mean eh C }}: \text { you.2SG.F meet.PTCP.SG.F this_way } \\
\text { 'I mean eh you meet people this way' }\end{array}$ & eople & & \\
\hline \multirow[t]{2}{*}{12} & personal pronoun & 19 & 0.112 & Within coordination structure \\
\hline & $\begin{array}{l}\text { aval e } \mathbf{C}: \text { hem amRu [G313] } \\
\text { but eh } \mathbf{C}_{\mathbf{:}} \text { they tell.PST.3PL.M } \\
\text { 'but eh they told (me to write down the details)' }\end{array}$ & & & \\
\hline \multirow[t]{2}{*}{13} & adjective $\quad \mathbf{C} \uparrow \quad$ conjunction & 12 & 0.111 & Within coordination structure \\
\hline & $\begin{array}{l}\text { ani mamaS gea } \mathrm{C} \uparrow \text { \# aval ha } \mathrm{C} \text { : XaveRim ba avoda } \ldots \\
\mathrm{I} \text { am really proud.F } \mathrm{C} \uparrow \text { \# but the } \mathrm{C} \text { : friends at work ... } \\
\mathrm{I} \text { am really proud but friends at work ... }\end{array}$ & & & \\
\hline
\end{tabular}

Table 1: Probabilities of the most probable trigrams with 10+ occurrences 


\section{Head and Dependant in the light of the results}

The relevance of DG to the present research is the possibility of linking the evidence presented, specifically the evidence concerning elongated words and dependency rules. To be more specific, should a link between form (C: boundary tone) and function (either head or dependent) be established, as in the following hypothetical rules:

- Should elongated personal pronouns be considered dependents of verb heads or any other predicates?

At least in IH analysis, it is helpful to remember that there may be confusion when using morphological dependency as a criterion for defining syntactical dependency. As Schneider (1998) notes, "Many linguists ... point out that the direction of the dependency is often unclear....[but] this is only one more confusion between syntactic and morphological dependency. E.g. the main verb and the grammatical subject can be said to mutually depend on each other" (ibid., 26). Or, in other words, "the subject determines the verb morphologically, while the subject depends on the verb syntactically" (ibid., 41).

- Should elongated articles, e.g. [ha] 'the', be considered dependents of noun heads?

According to Schneider, "For this construction it seems to be hardest to determine a head and no clear answer seems to emerge yet" (1998, 48). On the other hand, Hudson (1990, 268-276) suggests the determiner as head.

- Should elongated prepositions, e.g., [be] 'in', be dependents of noun heads.

- Should elongated subordinate conjunction [Se] 'that' be considered dependent of a more complex unit, the subordinate clause.

These last two points are not straightforward. In verbal clauses, both $P+N P$ (prepositional phrase) and $C O M P+S$ (subordinate clause) are verb complements, i.e. selected by the verb valence. While $\mathrm{P}$ assigns Case to NP or COMP assigns [+/-finite] to S, NP and S depend on the verb. Therefore, $\mathrm{P}$ and COMP can be parts of the nucleus. It can be said, therefore, that although dependency relations evolved from Tesnière's (1959) notion of verb valency, today valence is even attributed to lexicalized prepositions exactly the same way Tesnière treats functional words (Schneider 1998, 52). For example, in the sequence [halaX le tel aviv] 'went to Tel Aviv', the transitive verb [halaX-ø] 'go.PST-3SG.M' and the PP [le tel-aviv] 'to Tel Aviv' are analyzed as head [halaX le] 'went to' and dependent [tel aviv] 'Tel Aviv'.

- Should elongated conjunctions, e.g. [ve] 'and', be considered dependents of the two structures (i.e., conjuncts) they are coordinating.

This last point is problematic, since there is no coordination in dependency. "In pure dependency, coordination cannot be expressed. A dependency system will have to employ a constituency element like Tesnière's junctions" (Schneider 1998, 90). Therefore, for current dependency theories, coordination remains a very serious problem.

Following the above hypotheses and restrictions, to determine what is head and what is dependent remains an open question as the identical prosodic form does not suggest a similar cohesion in terms of dependency functions: For constructions like subject+verb, $A U X+V$ and $D E F+N$, perhaps even $C O M P+S$ and $P+N P$, "it is questionable ... if a clear dependent should be established, as both elements usually require each other. It is justifiable to think of them in terms of ... concomitance or to think of the first element in these constructions as a functional marker or head" (Schneider 1998, 53).

\subsection{Function words as heads in IH}

Since DG begins with the notion of the verb as the head, I will take a closer look at verbs in IH. Verbs are heads of items that saturate their valence, i.e. their arguments. Since elongated verbs were also found in the present research (as in (2)), a question emerges about the functional element within the verb that goes through elongation.
(2) asi-nu
e C: et ha tavoR [C614]
do.PST-1PL eh $\mathbf{C}:$ ACC the Tabor
'we tour eh Mount Tabor'

Indeed, the morphology of Hebrew verb structures (binyanim) has prefix and suffix conjugations that mark the person, and indicate gender and number (singular or plural) that are found in nouns. For example, the verb [asi-nu] 'do.PST-1PL', in (2) above, occurs in the cor- 
pus three times before a $\mathrm{C}$ : boundary. The suffix [-nu] '1PL' has the semantic meaning of the person and number (i.e., 'we'), which means that the elongated part is the subject. It was found to be elongated in separate structures (Table 1 lines 7 and 9), and can definitely be interpreted as a dependent of $\mathrm{V}$. Thus, the elongated part, when a morpheme, can be considered the functional element of the word as opposed to the substantive core element.

Another example is the gerund form in Hebrew (gerunds also have rich morphology, which is based on a root+template system). As applied to Hebrew, the term "gerund" refers either to the verb's action noun (Shem Pe'ula), or to the part of the infinitive following the infinitival prefix /le/ 'to'. Cases of elongated infinitival prefixes, shown in (3a)-(3h), also demonstrate the tendency of elongated elements to be part of functional (prefixes) vs. substantive elements (gerund):

(3) Infinitive prefixes,/le/ 'to', preceding $\mathrm{C}$ :

a. at jodaat le- $\mathbf{C}$ : le-Sapets oto ktsat ve ze [D341] 'you know (how) to- C: to-renovate it a little and this'

b. holeX li- C: kRot [C714]

going to- $\mathbf{C}$ : happen.INF

'is it going to happen'

c. ze mamaS \# jaXol la- C: le-halhiv otXa meod [G711]

it really \# can to- C: to-excite ACC.2SG.M very 'it really can excite you very much'

d. hu tsaRiX le- C: le-hotsi Xultsot CN [G831] he need to- C: to-get_out shirts CN 'he needs to to get the shirts out'

e. ani holeXet aXSav le- C: sadeR [G831] 'I am going now to- $\mathbf{C}$ : tide.INF'

f. ve holeXet 1- la- C: haSlim et kol Sot ha Sena [D341]

'and going t- to- C: refill.INF all the missing sleeping hours'

g. ve laS- la- C: asot RoSem kaze [OCh] 'and @ - to- C: make.INF such an impression'

h. az hu nivXaR me ha $\mathbf{C}$ : SliXim be kanada le $\mathbf{C}:$ le-jatseg et ha $\mathbf{C}:$... [C612]

'so he was chosen from the $\mathbf{C}$ : diplomats in Canada to $\mathbf{C}$ : to-represent the $\mathbf{C}:$...'

Although these relatively few cases can be considered coincidental, I view them as evidence of function words that sometimes cling to the preceding words, and thus together create phonological words. This may be due to the speaker's (unconscious?) wish to utter his ideas unambiguously. Since the relations between the verb and its arguments determine the precise lexical meaning of the verb, or the several meanings of a specific verb (Stern 1994, 16-17), the meaning of that verb will be unambiguous only when an increment that neutralizes a possible ambiguity is uttered. For example, [holeXet le] 'going.F to' is an unambiguous verb as opposed to [holeXet] 'goes.F', which has an intransitive meaning as well. Such an explanation should also be relevant to the prosodic separation between the two parts of the infinitive, the infinitival prefix [le] 'to' and the gerund [sadeR] 'arrange', in the case of (3e).

The examples above suggest that the elongated category is a function element, which can be a word, a clitic, and even an affix, and that it can be interpreted as a dependent. However, viewing the elongated function elements as dependents is only one option for analysis, which suggests that the head element is uttered in a separate following IU, while C: boundaries are the most probable prosodic breaks within syntactic dependencies.

This mapping demonstrated that two main syntactic structures - phrases and clauses were challenged by $\mathrm{C}$ : boundaries, while the four other boundary tones $(\mathrm{C} \rightarrow, \mathrm{C} \uparrow, \mathrm{C} \uparrow \downarrow, \mathrm{C} \downarrow)$ usually occur between phrases and clauses.

\subsection{The second element of the dependen- cy}

I have attempted to explain the phenomenon of C: boundaries from the point of view of the "preceding" POS, i.e., the elongated POS, and to show that regularity exists in terms of word class (function words) and that the prosodic pattern of elongation can be explained in terms of form and function, i.e. head-dependent relations. Yet, another aspect of C-boundaries is the following POS, or more generally - the following syntactic structure. When Hudson (1993) compares constituency theory and dependency theory with respect to the load on working memory, he argues that dependency theory allows us to count the number of active dependencies, defining a dependency as active if either the head or the dependent are still awaited. An active dependency is satisfied as soon as the word concerned is encountered (Hudson, 1993, 275-279). At that point, the 
burden on the working memory decreases and more space remains for continuous processing of information. Thus, the $\mathrm{C}$ : boundary tone phenomenon can be explained by Hudson's "active dependency" as a working memory load that is about to be satisfied.

\section{The dependency feature}

According to the dependency approach adopted here, what is common to all elongated words is the fact that they imply continuity, regardless of whether they are dependents of heads or heads of dependents. What should be stressed here is that they share a [+dependency] syntactic feature. It can be said that what is actually elongated is not the word itself (or a syllable of the word), but the syntactic feature itself.

For example, the results of the present research show a noun to be defined with a [dependency] feature, since they do not tend to be elongated and since nouns tend to occur in phrase-final position rather than in phraseinitial position; a preposition, on the other hand, can be defined with [+dependency]; an intransitive verb with [-dependency], e.g. [halaX-ø] 'walk.PST-3SG.M', but a transitive verb with [+dependency], e.g. [halaX] 'go.PST3SG.M', as in [halaX le tel aviv] 'went to Tel Aviv'. Thus, the [+dependency] feature shows that "there is more to come", and to mark the communicative intentions of the speaker. It allows the speaker to think, either the head or the dependent are still awaited, by elongating structures. In my view, what is common to elongated grammatical elements is the [+dependency] feature. I will refer to these elongated increments as leads.

Lead will be used here as a generic term for a variety of syntactical increments that have the [+dependency] feature and that are to be followed by another syntactical increment. In the context of the present research, leads are sometimes marked prosodically by the $\mathrm{C}$ : boundary tone. I present the term lead since, as was demonstrated, the term head cannot always be attributed to the elongated POSs in the present study (e.g., elongated personal pronouns).

To sum up, one characteristic can be said to apply to the findings of the present research on spontaneous spoken Hebrew, that of "syntactic planning coming before lexical planning" (Blanche-Benveniste 2007, 61). Blanche-
Benveniste (2007) stated that recent studies "have ... given more grammatical and semantic importance to dysfluencies... Determiners and subjects signal the nature of the phrase-tocome, without any lexical inside. I suggest an explanation: speakers would give first the syntactic frame, with no lexical fillers, and they would only give the whole phrase, syntax and lexicon together, in a second time.... That is why getting rid of such phenomena is a linguistic mutilation." (Blanche-Benveniste 2007, 61-62). In this respect, excessive elongations are prosodic morphemes which also have a pronominal nature. This is to say that speakers first utter the syntactic frame - the lead with its [+dependency] feature, which is carried by the C: boundary tone with its pronominal nature. The lead is expected to be followed by a syntactic increment or a target word.

\section{Summary}

The present research attempted to describe and explain the phenomenon of excessive elongated forms by promoting prosody and prosodic patterns before the syntactic structures. The findings demonstrate a high measure of regularity of the C-boundary annotation, which can also be interpreted as regularity in spontaneous speech processing, in general, and in spontaneous spoken Hebrew, in particular.

The analysis was performed on results that showed different types of dependencies between POSs, or words, across C-boundaries. I tried to explain the dependencies through DG a syntactic theory that can refer to prosody (inter alia, Mertens 2011), and used the terms head and dependent to find a common feature of POSs that carry the C: boundary tone (i.e., the (pre-) elongated word). In this respect, the present research brought a new perspective of the prosodic form and function relation, which encompass all parts of linguistic increments.

Following these results, an explanation of the role of the C-boundary tones in general, and the phenomenon of continuous elongation in particular, is offered, suggesting that the C: boundary phenomenon can be explained as a tension between the prosodic and syntactic strata of language. More specifically, the tension occurs between a prosodic break (two intonation units: one that ends with the $C$ : tone and the following intonation unit) and the syntactic continuity, and is what enables both the 
speaker and the listener to process (spontaneous) speech. The prosody-syntax interface described above clarifies the structural role of prosody in speech, that focuses on the chaining of prosodic units to one another (and, through this, subsequently chaining dependent syntactic units); rather than on the hierarchal nature of prosodic units.

\section{References}

Anderson, S. R. 2005. Aspects of the theory of clitics. Oxford: Oxford University Press.

Anthony, L. 2007. Antconc version 3.2.1w. Center for English Language Education, Waseda University. Available from http://www.antlab.sci.waseda.ac.jp/index.html.

Blanche-Benveniste, C. 2007. Linguistic analysis of spoken language: The case of French language. In Spoken language corpus and linguistic informatics: Contributions of linguistics, applied linguistics, computer sciences, edited by Y. Kawaguchi, S. Zaima and T. Takagaki. Tokyo: Tokyo University of Foreign Studies.

Brown, K. E., and J. E. Miller, eds. 1996. Concise encyclopedia of syntactic theories. Oxford: Elsevier.

Carter, R., and M. McCarthy. 2006. Cambridge grammar of English: A comprehensive guide: Spoken and written English grammar and usage. Cambridge: Cambridge University Press.

$\mathrm{CoSIH}$ - The Corpus of Spoken Israeli Hebrew. Available from http://www.tau.ac.il/humanities/semitic/cosih.ht $\mathrm{ml}$.

Fraser, N. M. 1996. Dependency grammar. In Concise encyclopedia of syntactic theories, edited by K. E. Brown and J. E. Miller, 71-75. Oxford: Pergamon.

Fraser, N. M., G. G. Corbett, and S. McGlashan. 1993. Introduction. In Heads in grammatical theory, edited by G. G. Corbett, N. M. Fraser and S. McGlashan, 1-10. Cambridge: Cambridge University Press.

Fox, B., Y. Maschler, and S. Uhmann. 2006. A cross-linguistic study of self-repair in English, German, and Hebrew. Paper read at ICCA 2006, May 12, at Helsinki.

Goldberg, Y. in progress. Automatic Syntactic Processing of Modern Hebrew, PhD dissertation. Department of Computer Science, Ben Gurion University of the Negev, Beer Sheva.

Goldberg, Y. and M. Elhadad. 2010. Easy First dependency parsing of Modern Hebrew. SPMRL-2010 - a NAACL/HLT workshop on Statistical Parsing of Morphologically Rich Languages.

Hudson, R. A. 1993. Do we have heads in our minds? In Heads in grammatical theory, edited by G. G. Corbett, N. M. Fraser and S. McGlashan, 266-291. Cambridge: Cambridge University Press.

Hudson, R. A. 1996. Word grammar. In Concise encyclopedia of syntactic theories, edited by $\mathrm{K}$. E. Brown and J. E. Miller, 368-372. Oxford: Pergamon.

Izre'el, S. 2005. Intonation units and the structure of spontaneous spoken language: A view from Hebrew. Paper read at IDP05 - International Symposium on "Towards modeling the relations between prosody and spontaneous spoken discourse", at Aix-en-Provence, France.

Izre'el, S. 2010. The basic unit of language: A view from spoken Israeli Hebrew. In Proceedings of the international workshop on Afroasiatic languages, 55-89. Japan: Tsukuba University.

Izre'el, S. and A. Mettouchi. Forthcoming. Representation of Speech in CorpAfroAs: Transcriptional Strategies and Prosodic Units. publication of CorpAfroAs: The Corpus of AfroAsiatic Languages (http://corpafroas.tge-adonis.fr/Home.html).

Ladd, D. R. 1996. Intonational phonology. Cambridge: Cambridge University Press.

Mertens, P. 2011. Prosodie, syntaxe, discours: autour d'une approche prédictive. in: Yoo, H-Y and Delais-Roussarie, E. (eds.), Actes d'IDP 2009, Paris, Septembre 2009, ISSN 2114-7612, pp. 19-32.

Rosén, H. B. 1977. Contemporary Hebrew. The Hague: Mouton.

Schneider, G. 1998. A linguistic comparison of constituency, dependency and link grammar. Master's thesis, University of Zurich.

Selkirk, E. 1995. The prosodic structure of function words. Available from http://people.umass.edu/selkirk/pdf/PSFWUMO P\%27\%20copy.pdf.

Silber-Varod, V. 2010. Phonological aspects of hesitation disfluencies. Speech Prosody 2010, May 14-19, Chicago, USA.

Steedman, M. 2001. Information structure and the syntax-phonology interface. Linguistic Inquiry 31(4): 649-685.

Stern, N. 1994. Dictionary of Hebrew verbs: The valence and distribution of the verb in contemporary Hebrew. Ramat Gan: Bar Ilan University Press (in Hebrew).

Tesnière, T. 1959. Éléments de syntaxe structurale. Klincksieck, Paris. 